\title{
Electromechanical Properties of Ethylene Propylene Diene Elastomers: Effect of Ethylene Norbornene Content
}

\author{
Patcharee Intanoo $^{1}$, Anuvat Sirivat ${ }^{1 *}$, Ruksapong Kunanuruksapong ${ }^{1}$, Wanchai Lerdwijitjarud ${ }^{2,3}$ \\ ${ }^{1}$ The Petroleum and Petrochemical College, Chulalongkorn University, Bangkok, Thailand; ${ }^{2}$ Department of Materials Science and \\ Engineering, Faculty of Engineering and Industrial Technology, Silpakorn University, Nakhon Pathom, Thailand; ${ }^{3}$ National Center \\ of Excellence for Petroleum, Petrochemicals, and Advanced Materials, Chulalongkorn University, Bangkok, Thailand. \\ Email: anuvat.s@chula.ac.th
}

Received December 24 $4^{\text {th }}, 2010$; revised March $21^{\text {st }}, 2011$; accepted March $24^{\text {th }}, 2011$.

\begin{abstract}
Ethylene propylene diene elastomers (EPDM) of various side chains and molecular weights were prepared as thin discs and the effects of electric field strength and temperature on the electromechanical properties were investigated. The electrical conductivity, the dielectric constant, the storage and loss moduli $\left(G^{\prime}\right.$ and $\left.G^{\prime \prime}\right)$, the storage modulus response $\left(\Delta G_{1000 \mathrm{~V} / \mathrm{mm}}^{\prime}\right)$, and the storage modulus sensitivity $\left(\Delta G_{100 \mathrm{~V} / \mathrm{mm}}^{\prime} / G_{0}^{\prime}\right)$ of the elastomers of different ethylene norbornene $(E N B)$ contents and molecular weights were measured under electric field strengths varying from $0 \mathrm{~V} / \mathrm{mm}$ to 1000 $\mathrm{V} / \mathrm{mm}$ and at temperatures between $300 \mathrm{~K}$ and $380 \mathrm{~K}$. The storage modulus response and sensitivity increase with increasing molecular weight and dielectric constant, consistent with the existing theory. However, for the case of EPDMs with different ENB contents, the storage modulus response and sensitivity vary inversely with the dielectric constant. EDPM is potentially a new type of electroactive materials.
\end{abstract}

Keywords: Dielectric Elastomer, Dipole Moment, Polar Molecule, Unsaturated Structure, Ethylene Propylene Diene Elastomers (EPDM), Electrorheological Properties

\section{Introduction}

Dielectric materials typically have poor electrical conductivity; they are widely used in capacitors [1], in electroactive polymers (EAP), and in dielectric elastomer actuators (DEAs). DEA applications have been proposed as large displacement actuators for use in micromechanical devices since they are simple, potentially low cost, and lightweight [2]. Dielectric elastomers typically consist of polar molecules with random orientations when electric field is not applied. An applied electric field will interact with the polar molecules by orienting the dipole moments [3]. Due to the induced dipole moments, some dimensional changes are expected in such a way that the EAPs transform electrical energy into a mechanical response. Examples of dielectric elastomers are ethylene propylene diene elastomers [4], silicone elastomers [5], and polyurethane [6].

Acrylic acid and silicone are also common dielectric elastomers. These actuators have been shown to have excellent actuation properties: large strains up to $380 \%$; high energy densities, up to $3.4 \mathrm{~J} / \mathrm{g}$; high efficiency; high response speed, and good reliability and durability [5].

Kyokane et al. [6] studied the electro-striction effect of a normal polyurethane elastomer (PUE) functionalized with a hydroxyl group (doped PUE); displacements increased with increasing applied voltage. The bending of the doped PUE films was larger than those of the normal PUE films, thus allowing operation at a lower voltage. The actuation mechanism is the deformation of the polymer networks, as induced by the dipole orientation of electrically mobile elements in the elastomer [7].

Feher et al. [8] studied the bending of a $\mathrm{TiO}_{2}$-loaded polydimethylsiloxane (PDMS) gel measured in a uniform and a non-uniform electric field. The gel cylinder between tow parallel copper electrodes gradually bent toward the cathode. The bending behavior was reversible, when positive and negative electrodes were alternated. As one of the electrodes was modified to create a non- 
uniform electric field (a metal ball replaced one of the electrodes) the bending was the same. Li et al. [9] studied the mechanical properties and electrical conductivities of a TiN- $\mathrm{Al}_{2} \mathrm{O}_{3}$ nanocomposite. The electrical resistivity decreased with an increasing amount of TiN, and the bending also increased with increasing amount of TiN.

Yun et al. [10] studied the performance of electroactive papers (EAPap) of various thicknesses: 20,30, and $40 \mu \mathrm{m}$. EAPap actuators exhibited a bending deformation in the presence of an electric field. Bassil et al. [11] studied the bending mechanism of gel actuators (PAAM) caused by the $\mathrm{pH}$ gradient induced by an electric field; the gel actuator showed a volume change upon a change in its environmental conditions. The thickness of the actuator increased, but it needed more electrical energy to move. Watanabe et al. [12] studied the electromechanical responses of pure polyurethane with compliant electrodes. The responses were due to the differences in charge densities between the anode and the cathode. Wissler et al. [13] reported the dielectric constants of different prestretched VHB 4910 membranes; the values decreased with increasing pre-stretched ratio. Hiamtup et al. [14] studied the dielectrophoresis force of polymer blends of polyaniline and polydimethylsiloxane with fixed copper electrodes, whereby the dielectrophoresis force increased with increasing electric field strength, but decreased with increasing polyaniline concentration.

In this present work, we investigate the electromechanical responses of two classes of EPDM elastomers: EPDMs with different ENB contents, and EPDMs with different molecular weights. We determine the storage modulus response $\left(\Delta G_{1000 \mathrm{~V} / \mathrm{mm}}^{\prime}\right)$ and the storage modulus sensitivity $\left(\Delta G_{1000 \mathrm{v} / \mathrm{mm}}^{\prime} / G_{0}^{\prime}\right)$ subject to various electric field strengths and the storage modulus response $\left(\Delta G_{100 \mathrm{rad} / \mathrm{s}}^{\prime}\right)$ subject to various temperatures.

\section{Experimental}

\subsection{Materials}

The ethylene propylene diene (EPDM) elastomers used were: NORDEL IP $3670(\% \mathrm{ENB}=1.8$, and $\mathrm{MW}=$ 210 000), NORDEL IP $4570(\% \mathrm{ENB}=4.9$, and $\mathrm{MW}=$ $210000)$, and NORDEL IP $5565(\% \mathrm{ENB}=7.5$, and MW $=210000)$ of different ENB contents; and, NORDEL IP $4570(\% \mathrm{ENB}=4.9$, and $\mathrm{MW}=210000)$, NORDEL IP $4520(\% \mathrm{ENB}=4.9$, and $\mathrm{MW}=115000)$, and NORDEL IP $4640(\% \mathrm{ENB}=4.9$, and $\mathrm{MW}=160000)$ of different molecular weights were all provided by Chemical Innovation Co., Ltd.. The properties of the elastomers are listed in Table 1.

\subsection{Preparation of Specimens}

All elastomer specimens were fabricated through solution casting. The elastomers were dissolved in hexane at $30 \% \mathrm{vol} / \mathrm{vol}$. The solutions were cast onto molds and the solvent was eliminated under a vacuum atmosphere at $300 \mathrm{~K}$ for 48 hours. Each sample was cut into a thin disc (diameter $\approx 2.5 \mathrm{~mm}$, and thickness $\approx 1.0 \mathrm{~mm}$ ).

\subsection{Characterization and Testing}

The specific conductivity was measured by a resistivity test fixture (Keithley 8009) connected to a voltage supplier (Keithley, model 6517A) whose voltage was varied and the resultant current was measured. The conductivity measurement was performed under atmospheric pressure, $40 \%$ to $60 \% \mathrm{RH}$, at 25 to $27^{\circ} \mathrm{C}$, in the linear Ohmic regime. The voltage and the current in the liner regime were

Table 1. Comparison of storage modulus responses $\left(\Delta G^{\prime}\right)$ and sensitivities $\left(\Delta G^{\prime} / G_{0}^{\prime}\right)$ of the EPDM films.

\begin{tabular}{|c|c|c|c|c|c|c|c|c|c|c|}
\hline Materials & $\%$ ENB & $\begin{array}{c}\mathbf{M}_{W} \\
(\mathrm{~g} / \mathrm{mol})\end{array}$ & $\begin{array}{l}\text { Density } \\
\left(\mathrm{g} / \mathbf{c m}^{3}\right)\end{array}$ & $\begin{array}{c}\mathbf{T}_{\mathrm{d}} \\
\left({ }^{\circ} \mathbf{C}\right)\end{array}$ & $\begin{array}{c}\text { Storage } \\
\text { modulus } \\
\mathrm{G}^{\prime}(\mathrm{Pa})\end{array}$ & $\begin{array}{l}\text { Storage } \\
\text { modulus } \\
\text { response } \\
\Delta G^{\prime}(\mathrm{Pa})\end{array}$ & $\begin{array}{c}\text { Storage } \\
\text { modulus } \\
\text { sensitivity } \\
\left(G^{\prime} / G_{0}^{\prime}\right)\end{array}$ & $\begin{array}{l}\text { Relative } \\
\text { dielectric } \\
\text { constant } \\
\left(\varepsilon^{\prime}\right) \text { at low } \\
\text { frequency }\end{array}$ & $\begin{array}{c}\text { Induction } \\
\text { time } \tau_{\text {ind }} \\
(s)\end{array}$ & $\begin{array}{c}\text { Recovery } \\
\text { time } \tau_{\text {rec }} \\
\text { (s) }\end{array}$ \\
\hline $\begin{array}{c}\text { NORDEL } \\
\text { IP } 3670\end{array}$ & 1.8 & 210000 & 0.86 & 457 & $1.84 \times 10^{5}$ & $4.34 \times 10^{5}$ & 0.383 & 1.24 & 1331 & - \\
\hline $\begin{array}{l}\text { NORDEL } \\
\text { IP } 4570\end{array}$ & 4.9 & 210000 & 0.86 & 450 & $1.59 \times 10^{5}$ & $3.99 \times 10^{5}$ & 0.178 & 1.86 & 1270 & - \\
\hline $\begin{array}{l}\text { NORDEL } \\
\text { IP } 5565\end{array}$ & 7.5 & 210000 & 0.86 & 442 & $8.22 \times 10^{4}$ & $9.65 \times 10^{4}$ & 0.140 & 1.91 & 3735 & - \\
\hline $\begin{array}{l}\text { NORDEL } \\
\text { IP } 4520\end{array}$ & 4.9 & 115000 & 0.86 & 440 & $6.88 \times 10^{4}$ & $1.24 \times 10^{4}$ & 0.149 & 1.50 & 4462 & - \\
\hline $\begin{array}{l}\text { NORDEL } \\
\text { IP } 4640\end{array}$ & 4.9 & 160000 & 0.86 & 450 & $7.35 \times 10^{4}$ & $4.86 \times 10^{4}$ & 0.155 & 1.49 & 4038 & - \\
\hline $\begin{array}{c}\text { NORDEL } \\
\text { IP } 4570\end{array}$ & 4.9 & 210000 & 0.86 & 450 & $1.59 \times 10^{5}$ & $3.99 \times 10^{5}$ & 0.178 & 1.86 & 1270 & - \\
\hline
\end{tabular}


converted to electrical conductivity by the following equation: $\sigma=1 / \rho=1 /\left(6.44 \times 10^{-5} \times R \times t\right)$, where $\sigma$ is the specific electrical conductivity $(\mathrm{S} / \mathrm{cm}), \rho(\rho=V / I)$ is the specific electrical resistivity $(\Omega \cdot \mathrm{cm}), t$ is the thickness of a sample pellet $(\mathrm{cm}), V$ is the applied voltage (Voltage drop) $(\mathrm{V})$, and $I$ is the measured current (A). All thicknesses samples of the samples were measured by using a thickness gauge.

The effects of electric field strength and temperature (between 300 and $380 \mathrm{~K}$ ) on the electromechanical properties were measured by a parallel plate fixture with diameter of $25 \mathrm{~mm}$ attached to a melt rheometer (Rheometric, ARES) and the thickness of the prepared elastomers of about $1 \mathrm{~mm}$. A DC voltage was applied through a DC power supply (Instek, GFG 8216A). A digital multimeter (Tektronic, CDM 250) was used to monitor the voltage input (Figure 1(b)). Dynamic strain sweep tests were first carried out to determine appropriate strain by measure $G^{\prime}$ and $G^{\prime \prime}$ in the linear viscoelastic regime at a 1.0 $\mathrm{rad} / \mathrm{s}$ frequency. The appropriate strains were determined to be $0.2 \%, 0.06 \%$, and $0.3 \%$ for the NORDEL IP 3670 , 4570 , and 5565, respectively, and $0.06 \%, 0.05 \%$, and $0.2 \%$ for the NORDEL IP 4570, 4520, and 4640, respectively. For the temporal response testing, the dynamic moduli $\left(G^{\prime}\right.$ and $\left.G^{\prime \prime}\right)$ were measured as functions of time with electric field on and off. The temporal $\mathrm{G}^{\prime}$ response of all elastomers was determined at $\mathrm{T}=300 \mathrm{~K}$. Frequency sweep tests were carried out to measure the $G^{\prime}$ and $G^{\prime \prime}$ of each sample as functions of frequency and temperature. The deformation frequency was varied from 0.1 to $100 \mathrm{rad} / \mathrm{s}$. In each measurement, the electric field was applied to the EPDM elastomer for $50 \mathrm{~min}$ to ensure the steady state condition before the $G^{\prime}$ and $G^{\prime \prime}$ measurements.

The dielectric constant values were measured by an LCR meter (HP, model 4284A) connected to the melt rheometer (Rheometric, ARES) with a $25 \mathrm{~mm}$ parallel plate fixture with a diameter of $25 \mathrm{~mm}$; the thickness of the prepared elastomers was about $1 \mathrm{~mm}$. The top and bottom sides of the specimens were coated with a silver adhesive to improve the electrical contact between the specimens and the electrodes. The measurements were carried at a temperature of $300 \mathrm{~K}$.

\section{Results and Discussion}

\subsection{Temporal Responses of the EPDM Elastomer Films}

The temporal responses of all of all EPDM elastomer films were studied at $E=1 \mathrm{kV} / \mathrm{mm}, \omega=100 \mathrm{rad} / \mathrm{s}, T=$ $300 \mathrm{~K}$, and \%strain $=0.3$ and 0.06 (Figure 2(a)). All elastomer samples were pre-sheared at a low frequency, and then the electric field was applied for $50 \mathrm{~min}$ to en-

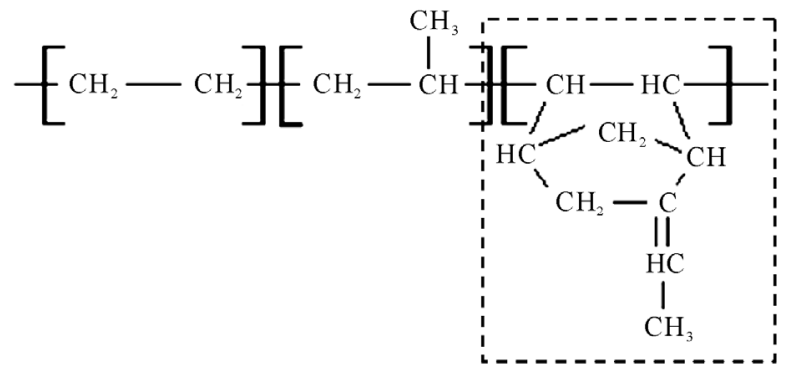

Ethylidene Norbornene, ENB side chain

(a)

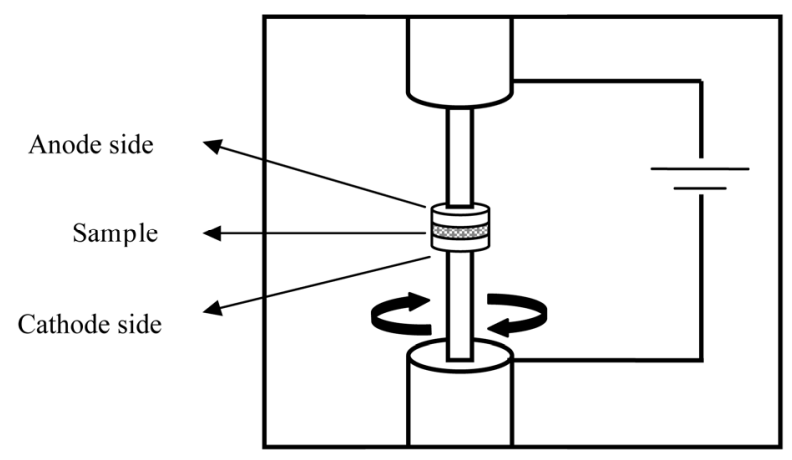

(b)

Figure 1. (a) Chemical structure of ethylene propylene diene elastomer (EPDM) with ethylidene norbornene, ENB side chain. (b) Schematic illustration of a test apparatus for the electromechanical properties measurement.

sure the formation of equilibrium polarization before the $G^{\prime}$ measurement. As can be seen in the Figure 2(a), $G^{\prime}$ increases with electric field on, and remains constant with electric field off. The increase in $G^{\prime}$ with the electric field on is due to the induced dipole moments generated on the unsaturated bond on the side chain. Electrostatic interaction between the dipole moments occurs leading to intermolecular interaction in the elastomer molecules; thus the increase in $G^{\prime}$. (The Maxwell stress is not operative here since our electrodes were fixed [15].) As the electric field is turned off, $G^{\prime}$ does not recover, suggesting that the EDPM material systems are irreversible, possibly due to residue dipole moments. The induction time and the recovery time of the NORDEL IP 5565 are 3735 and $0 \mathrm{sec}$, respectively, in the steady state. The NORDEL IP 4570 has an induction time and a recovery time of 1270 and $0 \mathrm{sec}$, respectively, in the steady state. The induction times and the recovery times of both NORDEL IP 5565 and NORDEL IP 4570 are thus comparable. Wichiansee et al. [16] reported on the temporal response of crosslinked PDMS at an electric field strength of $1 \mathrm{kV} / \mathrm{mm}$; effect of electric field strength on $G^{\prime}$. It was also an irreversible system due to some residue dipole moments between the PDMS molecules. Puvanatvattana et al. [17] 


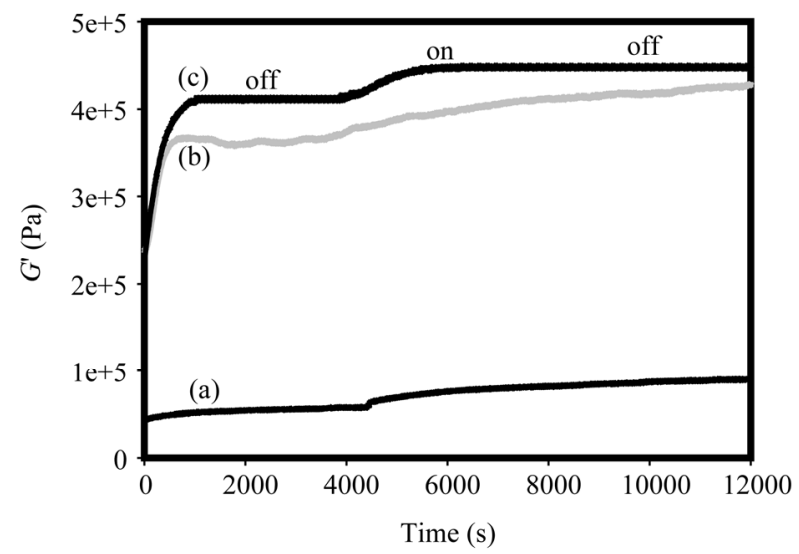

(a)

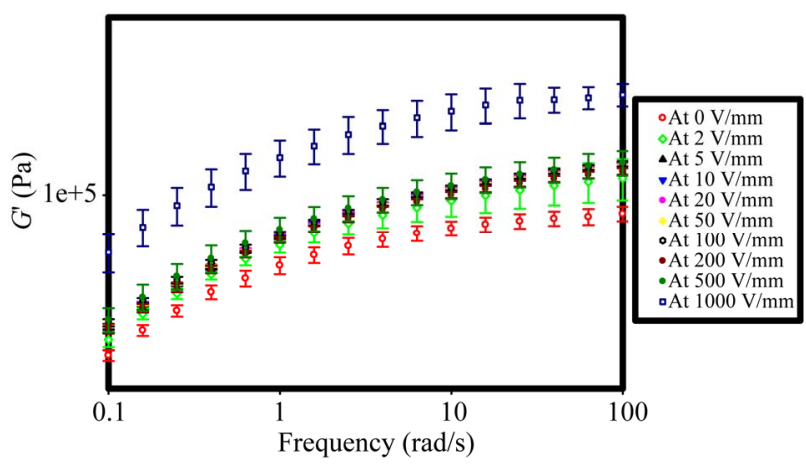

(b)

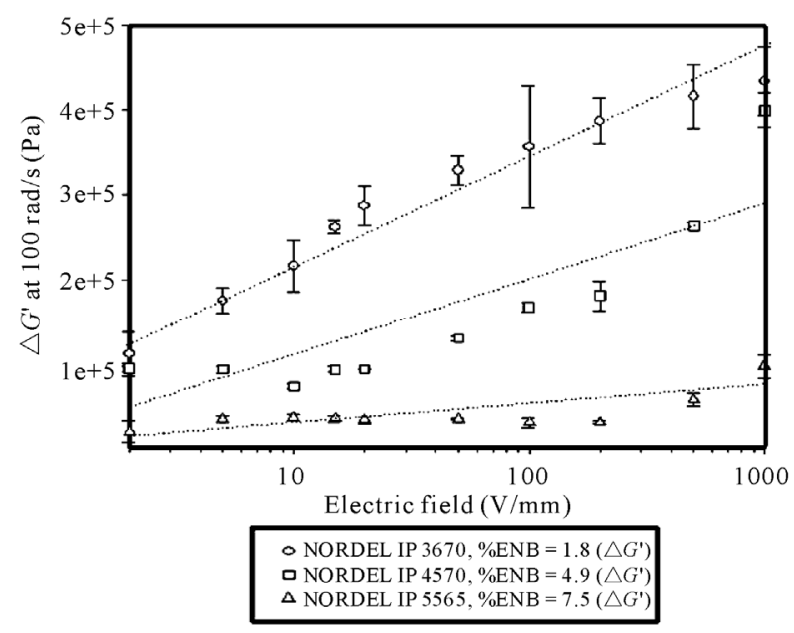

(c)

Figure 2. (a) Storage modulus $\left(G^{\prime}\right)$ at $100 \mathrm{rad} / \mathrm{s}$ and $1 \mathrm{kV} /$ mm versus time of the EPDM films with different ENB contents: (a) NORDEL IP 5565; (b) NORDEL IP 4570; and (c) NORDEL IP 3670. (b) Storage modulus $\left(G^{\prime}\right)$ at $T=300$ $\mathrm{K}$ and \%strain $=0.3$ versus frequency of the NORDEL IP 5565 film at various electric field strengths. (c) Storage modulus responses $\Delta G^{\prime}$ ) at $T=300 \mathrm{~K}, \omega=100 \mathrm{rad} / \mathrm{s}$, and \%strain $=0.3$ of the EPDM films of various ENB contents versus electric field strength. studied the temporal response of Pth_U20/PI_03; it, too, was an irreversible system, due to some irreversible interactions between the polythiophene particles (perhaps hydrogen bonding between adjacent polythiophene particles, and residual dipole moments inducing permanent interparticle interactions).

\subsection{Effect of Electric Field Strength on the Physical Properties}

The specific electrical conductivity values of the NORDEL IP 3670, 4570, 5565, 4520, and 4640 at a temperature of $300 \mathrm{~K}$ are $1.12 \times 10^{-7}, 4.31 \times 10^{-7}, 4.94 \times 10^{-7}$, $1.20 \times 10^{-7}$, and $2.53 \times 10^{-7} \mathrm{~S} / \mathrm{cm}$, respectively. The specific electrical conductivities increase with increasing diene contents due to more conjugated $\pi$ - electron systems in the structure; the electrical conductivity also increases with decreasing molecular weights due to a smaller free volume and the ease of electrons to move.

The effect of electric field on the electromechanical properties of the EPDM elastomer films was studied at $T=$ $300 \mathrm{~K}$ with the electric field strength varying between 2 and $1000 \mathrm{~V} / \mathrm{mm}$. The storage modulus $\left(G^{\prime}\right)$ versus frequency of the EPDM elastomer film (NORDEL IP 5565) is shown in Figure 2(b). It can be seen that the storage modulus increases with increasing electric field strength at all frequencies examined. Polarization is generated on the unsaturated bonds on the side chain of the EPDM elastomer, inducing dipole moments. This leads to an increase in the storage modulus, consistent with the modified Hooke's law [18]:

$$
\delta=-Q \varepsilon_{0}^{2}(\varepsilon-1)^{2} E^{2} Y
$$

where $\delta$ is the stress, $Q$ is the electrostriction coefficient, $\varepsilon$ is the dielectric permittivity of the material, $\varepsilon_{0}$ is the dielectric constant of free space $(8.85 \mathrm{pF} / \mathrm{m}), E$ is the electric field strength $(\mathrm{V} / \mathrm{m})$, and $\mathrm{Y}$ is the Young's modulus. From this equation, the stress varies linearly with the square of the electric field strength [18].

Figure 2(c) shows the storage modulus responses, $\Delta G^{\prime}(\omega=100 \mathrm{rad} / \mathrm{s})$, of EDPM of various ENB contents, $\Delta G^{\prime}$ generally increases linearly with increasing electric field strength. Furthermore, $\Delta G^{\prime}$ as shown in Figure 2(c) decreases with ENB content and attains the maximum values of $4.34 \times 10^{-5} \mathrm{~Pa}$, for the NORDEL IP 3670 at $E$ $=1 \mathrm{kV} / \mathrm{mm}$. This finding suggests that as more ENB side chains are available, they create an overall larger free volume and, hence, reduces the dipole moment interaction at a given electric field. On the other hand, $\Delta G^{\prime}$ increases with increasing molecular weight and attains the maximum value of $3.99 \times 10^{-5} \mathrm{~Pa}$, for the NORDEL IP 4570 at $E=1 \mathrm{kV} / \mathrm{mm}$. An EPDM with a higher molecular weight has a smaller number of free ends, and therefore a smaller free volume and hence a more effective 
dipole moment interaction. For the storage modulus sensitivities, $\Delta G^{\prime} / G_{0}^{\prime}$, of EPDM of various ENB contents and molecular weight contents, similar results to $\Delta \mathrm{G}^{\prime}$ are found and the sensitivity attains the maximum values of 0.38 and 0.18 , respectively. Table 1 summarizes the data and the findings with respect to the effects of ENB content and molecular weight.

\subsection{Effect of Temperature on the Electromechanical Properties}

The effect of temperature on the electromechanical properties of the EPDM films was studied at electric field strengths between 0 and $1 \mathrm{kV} / \mathrm{mm}$ versus frequency within the temperature range of $300 \mathrm{~K}$ to $380 \mathrm{~K}$ (Figure 3(a)). The storage moduli $\left(G^{\prime}\right)$ of the EDPM elastomers of different molecular weight contents are shown in Figure 3(b) at an electric field of $1 \mathrm{kV} / \mathrm{mm}$, and $\omega=100 \mathrm{rad} / \mathrm{s}$, within the temperature range between $300 \mathrm{~K}$ and $380 \mathrm{~K}$. It can be seen that $\mathrm{G}^{\prime}$ increases with increasing temperature only at high frequencies. In the case of the EPDM elastomers of different molecular weights a similar result occurs, consistent with the classical network theory [19]:

$$
G^{\prime}=v k_{B} T
$$

where $k_{B}$ is Bolzmann's constant, $T$ is the absolute temperature $(\mathrm{K})$, and $v$ is the crosslink density $\left(1 / \mathrm{cm}^{3}\right)$. As temperature increases, the entropy of the elastomer increases [19]; the molecules vibrate more vigorously, hence generating a greater retractive force on the network. The increase in $G^{\prime}$ at high frequencies can thus be traced back to the elastomeric backbone of the EDPM. On the other hand, $G^{\prime}$ decreases with increasing temperature at low frequencies; this behavior reflects the fact that the ENB side chain is thermoplastic in origin.

From Figures 3(b), it can be seen that generally $\Delta G^{\prime}$ (100 rad/s, $1 \mathrm{kV} / \mathrm{mm}$ ) increases linearly with temperature, consistent with Equation 1, and attains maximum values of $3.12 \times 10^{5}, 2.48 \times 10^{5}$, and $1.87 \times 10^{5} \mathrm{~Pa}$ for the NORDEL IP 4570, 4640, and 4520, respectively, at a temperature of $380 \mathrm{~K}$. Kunanuruksapong et al. [20] reported that $\left(\Delta G^{\prime}\right)$ and $\left(\Delta G^{\prime} / G_{0}^{\prime}\right)$ of acrylic elastomers increased with increasing temperature at a frequency of 1 $\mathrm{rad} / \mathrm{s} . \Delta G^{\prime}$ and $\Delta G^{\prime} / G_{0}^{\prime}$ of styrene copolymer increased initially and then decreased at temperatures above $T_{g}$ [20], because at temperatures above $T_{g}$, the materials change from a rubbery -like state to a plastic-like state [20]. Sato et al. [21] studied the rheological properties of a styrene copolymer (SIS triblock copolymer) in n-tetradecane as a function of frequency and temperature without an electric field. At low temperature ( $T<T_{g}$ of the styrene segment), the styrene behavior is still rubbery-like. But, with increasing temperature ( $T>T_{g}$ of styrene segment), the system behavior became plastic and viscous-like. Puva-

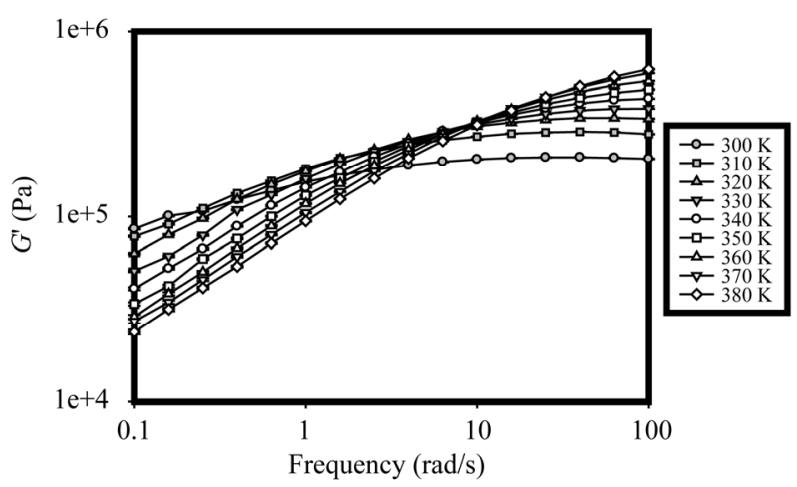

(a)

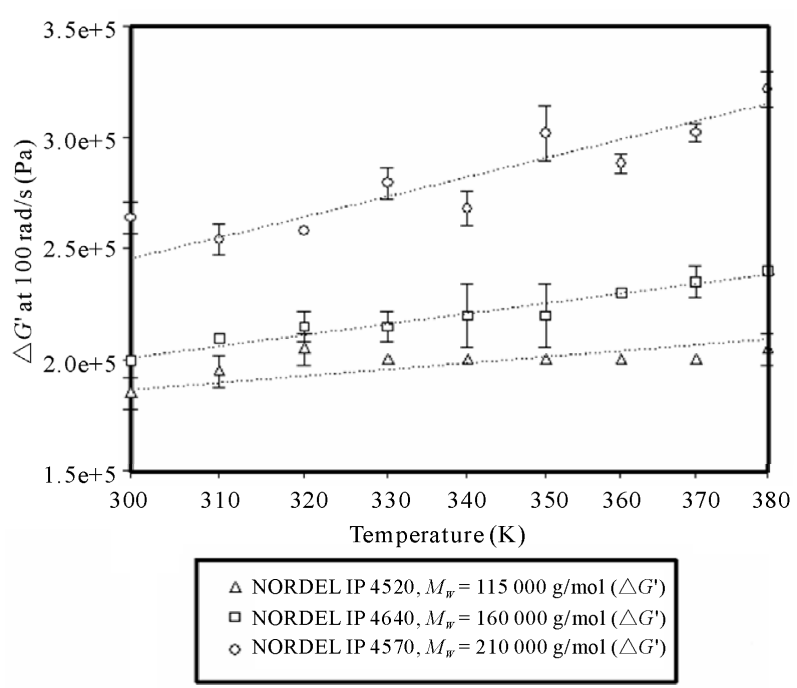

(b)

Figure 3. (a) Storage modulus $\left(G^{\prime}\right)$ at $100 \mathrm{rad} / \mathrm{s}, 0 \mathrm{kV} / \mathrm{mm}$, and \%strain $=0.5$ versus frequency of the NORDEL IP 5565 films at various temperatures $(100 \mathrm{rad} / \mathrm{s}, 0 \mathrm{kV} / \mathrm{mm}$, and $\%$ strain $=0.5$ ). (b) Storage modulus responses $\Delta G^{\prime}$ ) at $100 \mathrm{rad} / \mathrm{s}$, at $1 \mathrm{kV} / \mathrm{mm}$, and \%strain $=0.03$ of the EPDM films of various molecular weights versus temperature.

natvattana et al. [17] reported the $\Delta G^{\prime}$ of various crosslinked polyisoprene systems as functions of electric field strength at a frequency of $1 \mathrm{rad} / \mathrm{s} ; \Delta G^{\prime}$ increased with increasing electric field strength. Fox et al. [22] reported that the displacement of the dielectric elastomer membrane was highest when a large inflated state and low frequencies were used; the displacement droped off rapidly, however, as frequency increased.

\subsection{Dielectric Constants of the EPDM Elastomers}

The dielectric constants of NORDEL IP 3670, 4570, 5565,4520 , and 4640 at $T=300 \mathrm{~K}$ and at a frequency of $100 \mathrm{~Hz}$ are $1.27,1.88,1.92,1.53$, and 1.53 , respectively. Figure 4 shows that the dielectric constants are inde- 


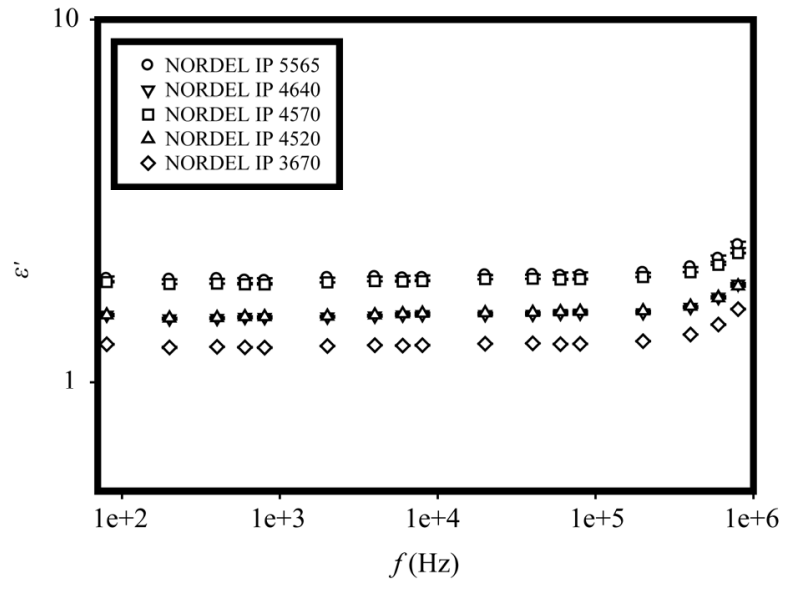

Figure 4. Relative dielectric constant $\left(\varepsilon^{\prime}\right)$ versus frequency of the EPDM films.

pendent of frequency. From the data tabulated in Table 1, it can be seen that the dielectric constant increases with ENB content as more side chains are available to create greater dipole moments or to store more charges. In addition, the dielectric constant increases with increasing molecular weight or with decreasing free volume, for the EDPM elastomers of different molecular weights.

The increases in the storage modulus responses and sensitivities, for the EDPM of various molecular weights, can be correlated with an increase in the dielectric constant, consistent with the existing theory [23]. On the other hand, the storage moduli and sensitivities, for EDPM of various ENB contents, monotonically decrease with increasing dielectric constant (Table 1). This reflects the fact that, as more side chains are available, even though creating a greater capability to store charges, the effect is outweighed by the resultant larger free volume of the material or a greater distance for the dipole moments to interact.

Hao et al. [24] studied the mechanical properties of starch/silicone oil/silicone rubber; they found that the $\Delta G^{\prime} / G_{0}^{\prime}$ first increased with silicone oil concentration and then decreased; the decrease was related to the fact that as the silicone oil concentration increased, the dipole-dipole distance increased and the electrostatic force decreased, which weakened the effect of the electric field on the storage modulus.

\section{Conclusions}

In this present work, the electromechanical properties of EPDM elastomers (NORDEL IP 3670, 4570, 5565, 4520, and 4640) were investigated by examining the effects of electric field strength and temperature on the dynamic storage modulus $\left(G^{\prime}\right)$ under oscillatory shear mode. The experiments were carried out at electric field strengths varying from 0 to $1 \mathrm{kV} / \mathrm{mm}$ in frequency and temperature sweep test modes. In our EPDM elastomers, there are unsaturated structures on the side chains, which can induce electrical dipole moments. The storage modulus responses $\left(\Delta G^{\prime}\right)$ and sensitivities $\left(\Delta G^{\prime} / G_{0}^{\prime}\right)$ increase with increasing both electric field and temperature (between $300 \mathrm{~K}$ and $380 \mathrm{~K}$ ) at high frequencies; the effect of temperature is due to the entropic contribution of the elastomeric matrices. The dielectric constant of NORDEL IP 5565 is the highest because there are more unsaturated structures on the side chains, which can generate more dipole moments.

\section{Acknowledgements}

The authors would like to acknowledge the financial support to A.S. from the Conductive and Electroactive Polymers Research Unit of Chulalongkorn University, the Thailand Research Fund (TRF-BRG), the National Center of Excellence for Petroleum, Petrochemical and Advanced Materials, and the Royal Thai Government (Budget of Fiscal Year 2552); and to Chemical Innovation Co., Ltd. for the materials: the NORDEL IP series. The support from the Department of Materials Science and Engineering, Faculty of Engineering and Industrial Technology, Silpakorn University, is also acknowledged.

\section{REFERENCES}

[1] C. Gerbo, "Future Materials," Australian National University, Canberra, March 2004.

[2] J. S. Plante and S. Dubowsky, "On the Performance Mechanisms of Dielectric Elastomer Actuators," Sensors and Actuators A: Physical, Vol. 137, No. 1, 2007, pp. 96- 109. doi:10.1016/j.sna.2007.01.017

[3] C. R. Nave, "Department of Physics and Astronomy," Georgia State University, Atlanta, 2005.

[4] J.-D. Nam, H.-R. Choi, J.-C. Koo, Y.-K. Lee and K.-J. Kim, "Dielectric Elastomers for Artificial Muscles," In: K.-J. Kim and S. Tadokoro, Eds., Electroactive Polymers for Robotic Applications, Springer, Berlin, 2007, pp. 3748. doi:10.1007/978-1-84628-372-7_2

[5] L. W. Liu, J. M. Fan, Z. Zhang, L. Shi, Y. J. Lin and J. S. Leng, "Analysis of the Novel Strain Responsive Actuators of Silicone Dielectric Elastomer," Advanced Materials Research, Vol. 47-50, 2008, pp. 298-301. doi:10.4028/www.scientific.net/AMR.47-50.298

[6] J. Kyokane, H. Ishimoto, H. Yugen, T. Hirai, T. Ueda and K. Yoshino, "Electro-Striction Effect of Polyurethane Elastomer (PUE) and Its Application to Actuators," Synthetic Metals, Vol. 103, No. 1-3, 1999, pp. 2366-2367. doi:10.1016/S0379-6779(98)00708-5

[7] K. Urayama, K. Kondo, Y. O. Arai and T. Takigawa, "Electrical Driven Deformations of Nematic Gels," Physics Reviews E, Vol. 71, No. 5, 2005, p. 051713. doi:10.1103/PhysRevE.71.051713 
[8] J. Feher, G. Filipcsei, J. Szalma and M. Zrinyi, "Bending Deformation of Neutral Polymer Gels Induced by Electric Fields," Colloid and Surface A: Physicochemical and Engineering Aspects, Vol. 183-185, No. 15, 2001, pp. 505515.

[9] J. Li, L. Gao and J. K. Guo, "Mechanical Properties and Electrical Conductivity of $\mathrm{TiN}-\mathrm{Al}_{2} \mathrm{O}_{3}$ Nanocomposites," Journal of European Ceramic Society, Vol. 23, No. 1, 2003, pp. 69-74. doi:10.1016/S0955-2219(02)00089-4

[10] S. Yun, J. Kim and C. Song, "Performance of ElectroActive Paper Actuators with Thickness Variation," Sensors and Actuators A: Physics, Vol. 133, No. 1, 2007, pp. 225-230.

[11] M. Bassil, J. Davena and M. Tahchi, "Electrochemical Properties and Actuation Mechanisms of Polyacrylamide Hydrogel for Artificial Muscle Application," Sensors and Actuators B: Chemistry, Vol. 134, No. 2, 2008, pp. 496501.

[12] M. Watanabe and T. Hirai, "Space Charge Distribution in Bending-Electrostrictive Polyurethane Films Doped with Salts," Journal of Polymer Science Part B: Polymer Physics, Vol. 42, No. 3, 2004, pp. 523-531. doi:10.1002/polb.10728

[13] M. Wissler and E. Mazza, "Electromechanical Coupling in Dielectric Elastomer Actuators," Sensors and Actuators A: Physics, Vol. 138, No. 2, 2007, pp. 384-393.

[14] P. Hiamtup, A. Sirivat and A. M. Jamieson, "Electromechanical Response of a Soft and Flexible Actuator Based on Polyaniline Particles Embedded in a Cross-Linked Poly (Dimethyl Siloxane) Network," Materials Science and Engineering C, Vol. 28, No. 11, 2007, pp. 10441051.

[15] R. Pelrine, R. Kornbluh, J. Joseph, R. Heydt, Q. Pei and S. Chiba, "High-Field Deformation of Elastomeric Dielectrics for Actuators," Materials Science and Engineering C, Vol. 11, No. 2, 2000, pp. 89-100. doi:10.1016/S0928-4931(00)00128-4

[16] W. Wichiansee and A. Sirivat, "Electrorheological Properties of Poly(Dimethylsiloxane) and Poly (3,4-Ethylenedioxy Thiophene)/Poly(Stylene Sulfonic acid)/Ethylene
Glycol Blends," Materials Science and Engineering C, Vol. 29, No. 1, 2009, pp. 78-84. doi:10.1016/j.msec.2008.05.018

[17] T. Puvanatvattana, D. Chotpattananont, P. Hiamtup, S. Niamlang, A. Sirivat and A. M. Jamieson, "Electric Field Induced Stress Moduli in Polythiophene/Polyisoprene Elastomer Blends," Reactive and Functional Polymers, Vol. 66, No. 12, 2006, pp. 1575-1588. doi:10.1016/j.reactfunctpolym.2006.06.001

[18] D. O. Diaconu, F. Dorohoi and T. Topoliceanu, "Electrostriction of a Polyurethane Elastomer-Based Polyester," IEEE Sensors Journal, Vol. 6, No. 4, 2006, pp. 876-880. doi:10.1109/JSEN.2006.877978

[19] M. Rubinstein and R. H. Colby, "Polymer Physics," Oxford University Press, New York, 2003.

[20] R. Kunanuruksapong and A. Sirivat, "Electrical Properties and Electromechanical Responses of Acrylic Elastomers and Styrene Copolymers: Effect of Temperature," Applied Physics A, Vol. 92, No. 2, 2008, pp. 313-320. doi:10.1007/s00339-008-4513-3

[21] T. Sato, H. Watanabe and K. Osaki, "Rheological and Dielectric Behavior of a Styrene-Isoprene-Styrene Triblock Copolymer in n-Tetradecane. 1. Rubbery-PlasticViscous Transition," Macromolecules, Vol. 29, No. 19, 1996, pp. 6231-6239. doi:10.1021/ma960060i

[22] J. W. Fox and N. C. Goulbourne, "On the Dynamic Electromechanical Loading of Dielectric Elastomer Membranes," Journal of Mechanic and Physics of Solids, Vol. 56, No. 8, 2008, pp. 2669-2686. doi:10.1016/j.jmps.2008.03.007

[23] T. Shiga and T. Kurauchi, "Deformation of Polyelectrolyte Gels under Influence of Electric Field," Journal of Applied Polymer Science, Vol. 39, 1990, pp. 2305-2330. doi:10.1002/app.1990.070391110

[24] L. Hao, Z. Shi and X. Zhao, "Mechanical Behavior of Starch/Silicone Oil/Silicone Rubber Hybrid Electric Elastomer," Reactive and Functional Polymers, Vol. 69, No. 3, 2009, pp. 165-169. doi:10.1016/j.reactfunctpolym.2008.12.014 